\title{
Vulvar Carcinoma
}

National Cancer Institute

\section{Source}

National Cancer Institute. Vulvar Carcinoma. NCI Thesaurus. Code C4866.

A carcinoma arising from the vulva. It usually affects elderly women but has been

observed in premenopausal women as well. The most frequently seen histologic type is squamous cell carcinoma. The most common site of involvement is the labia majora. In many cases, the development of vulvar cancer is preceded by condyloma or squamous dysplasia. 